Research letter

\title{
Current trends in growth processes in the population of young residents of the Northeast of Russia
}

\author{
Inessa V. Averyanova
}

Scientific Center “Arktika”, Magadan, Russia

Received 7 September 2018, Revised 17 October 2018, Accepted 21 January 2019

\author{
(C) 2018, Averyanova I.V. \\ (C) 2018, Russian Open Medical Journal
}

\begin{abstract}
Background - The purpose of this work was to study the manifestation of the secular trend in the population of young male residents of Magadan region.

Material and Methods - We examined 17-21 year old male residents of Magadan region ( $n=1,628)$. Depending on their terms of residence in the northeast we divided the subjects into four groups. The newcoming migrants, Caucasians by origin, all from the central parts of the country having a relatively short (in average, $7.1 \pm 1.3$ years) period of residence made up Group 1 ( $n=62$ ) and were considered as the "zero" generation. Group $2(n=918)$ was made up of Magadan region born Caucasians considered as the first generation whose parents were the migrants. Group $3(n=582)$ was young male residents born in the region as the second generation. Finally we referred the subjects born in the third generation to group $4(n=66)$. The research was aimed at ascertaining and analyzing the vector of change in basic somatometric values of physical development observed in young male residents of Magadan region depending on their term of residence in the territory. For the aim, we studied the series of direct somatometric characteristics and their predictive indices.

Results - As a result we could trace significant dynamics through nearly all the examined parameters and their predictive indices in the row from the zero to the third generation. Subjects from the third generation demonstrated reliably higher body mass, chest circumference and total fat values as compared to those of the other groups. In the studied row, a U-shaped trend was observed in the body length. Of note that subjects from the first and the second generations showed that parameter reliably lower than in the zero and the third generation subjects. In parallel with the growth of the body longitudinal size, the increase in the circumference indices as well as the body mass was found. The latter proved not to lead to the formation of an asthenic somatic type being typical of some populations in our country. Besides, changes in the body constitutional proportions were revealed in representatives of the current population of the third generation that could be mostly seen in the legs enlarging in comparison with the body length.

Conclusion - As a whole, results of the carried research testified to a secular trend in processes typical of the population inhabiting the territory of Magadan region. That proved to differ from the tendency described by authors of other regions who had observed the balancing in the young residents' growth processes. The changeability in somatometric values could be caused by social and economic alterations occurred in Magadan region in 1990s and 2000s.
\end{abstract}

Keywords: Magadan region, male Caucasians, physical development, secular trend

Cite as Averyanova IV. Current trends in growth processes in the population of young residents of the Northeast of Russia. Russian Open Medical Journal 2019; 8: e0102.

Correspondence to Inessa V. Averyanova. Address: Laboratory for Physiology of Extreme States, Scientific Center "Arktika", Karl Marx str. 24, Magadan, 685000, Russia. E-mail: Inessa1382@mail.ru. Tel.: +7 (924) 6911146.

\section{Introduction}

Indicators of physical development can be used as an indicator of nutritional status, living standards [1, 2], an indicator of the health and well-being of the inhabitants of a given country, and may reflect the state of socioeconomic development and the quality of the health system in the whole [1]. The basic characteristics of growth processes, such as body weight, body length, and chest circumference are the result of the evolutionary development of a person, and their variability is a reflection of the plasticity of the ontogenesis process [3]. There is an opinion that the main feature of human growth processes is its environmental sensitivity to a wide range of environmental influences [2]. Therefore, the Body Length indicator due to its "ecosensitivity" can be considered the main criterion of the population health state and the quality of the environment as a "sensitive indicator of the state of society" [3], as an indicator of overall well-being and even the moral state of society being a mirror of the processes taking place in the society [4]. At present body length is widely used in economic science and is recognized as a useful measure of human well-being [5]. Variability of somatometric characteristics, in particular the body length indicator, led biologists, anthropologists and experts from the World Health Organization (WHO) to conclude that external factors (nutrition, environmental conditions, climatic characteristics, etc.) are more likely to cause changes in body length indices [6, 7], since the genetic pool of the population is unlikely to change over short periods of time (30-70 years) [8]. An important role in the context of such studies is played by the study of body length as a "genetically controlled long process of adaptation in ontogenesis" [9] and the 
idea that the growth index is an adaptive ability of Homo sapiens occurs in almost all texts on biological adaptation of humans [10].

Studies of physical development are becoming particularly relevant nowadays since either in different countries of the world [11-13] or in the territory of Russia [14] there are multidirectional trends in the variability of morphofunctional indices. Thus, our work will be aimed at identifying vectors of variability of the basic somatometric indicators of physical development in young male people with different residence periods on the territory of Magadan region.

\section{Material and Methods}

By random sampling, 1,628 young men aged 17 to 21 years, permanent residents of Magadan Region, who are students of the Northeastern State University (Magadan, Russia), were examined. Depending on the duration of residence in the territory of Magadan Region, all the examinees were divided into 4 groups. Thus, the first group $(n=62)$ included newcoming migrantsCaucasians from the central regions of the country, characterized by a short residence in the North (on average $7.1 \pm 1.3$ years) who were designated as "zero generation". The second group included the surveyed natives of Magadan Region in the first generation of Caucasians, but whose parents were newcomers ( $n=918)$. The third group included young male people born in the North in the $2 n d$ generation $(n=582)$ whose parents were already natives of the region and born there in the 1st generation. And finally, the fourth group are those with the longest term of residence in Magadan region, who are representatives of the population that is just beginning to form (due to the relative "young age" of our region) these are young males of the third generation $(n=66)$ whose parents are representatives of the 2 nd generation. All studies were conducted in the period 2005-2017.

All the subjects underwent measurement of the basic somatometric parameters: body length and body weight, chest circumference. According to these data, the calculation of the Pignet index ( $\mathrm{PI}$, arb. units), characterizing the strength of the body build, was made. Also body proportionality index (BPI, \%), body mass index $\left(\mathrm{BMI}, \mathrm{kg} / \mathrm{m}^{2}\right)$, body area $\left(\mathrm{S}, \mathrm{cm}^{2}\right)$ and the ratio of body mass to body area $\left(\mathrm{BM} / \mathrm{S}, \mathrm{kg} / \mathrm{m}^{2}\right)$ were calculated. Determination of the total fat content (in \% of the body weight) was measured by the Diamant-AIST (Diamant, Russia) impedance body analyzer using the AIST software package.
The study was carried out in accordance with the principles of the Helsinki Declaration. The study protocol was approved by the Ethical Committee for Biomedical Research at the North-East scientific centre (NESC) of the Far East Branch of the Russian Academy of Sciences (No. 004/013 dated December 10, 2013). Prior to getting involved in the study, all participants gave written informed consent.

The results were statistically processed using the Statistica 7.0 application package. The normal distribution of the measured variables was checked based on the Shapiro-Wilk test. All data were normally distributed. The results of parametric processing methods are presented as the mean value (M), standard deviation (SD) and the error of the arithmetic mean $( \pm m)$. The statistical significance of the differences was determined using the Steffe criterion. The critical level of significance $(p)$ was assumed to be $0.05,0.01,0.001[14]$.

\section{Results}

Table 1 presents the main somatometric indicators for young men with different periods of residence in the territory of Magadan Region. The analysis of the obtained data presented in the table made it possible to establish that in the series from the zero to the 3rd generation there is a significant dynamics found for practically all somatometric indicators and their calculated indices. Indicators of body weight, chest circumference and total body fat in the examinees from the third generation are significantly higher than in those of other groups.

The subjects of the 0th and 3rd generation did not differ in the body length values, whereas the subjects from the 1st and 2 nd generations were characterized by statistically lower values of this indicator. There was a slight increase in BMI in the examined young males of the 4th group; however, the digital values of this indicator were within the reference range for all subjects.

The Pignet Index also had lower values in the group of representatives of the 3 rd generation which reflected an increase in the degree of strength of the body build. At the same time, statistically lower indices of the body build proportionality index (BPI) were demonstrated by the subjects from the 0th, 1st and 2nd generations which indicated a smaller length of legs as compared to the Body Length than in the subjects from the 3rd generation. Also in the 3rd generation, the highest values of body area (S) and the ratio of body mass to body area (BM/S) were recorded.

Table 1. Somatometric indicators in subjects with different residence time in the North-East of Russia

\begin{tabular}{|c|c|c|c|c|c|c|c|c|c|c|}
\hline \multirow[t]{2}{*}{ Indicators } & \multicolumn{4}{|c|}{ Groups } & \multicolumn{6}{|c|}{ P-level (significance of differences among groups) } \\
\hline & $\begin{array}{l}\text { Oth generation } \\
(1), n=62\end{array}$ & $\begin{array}{l}\text { 1st generation } \\
(2), n=918\end{array}$ & $\begin{array}{l}\text { 2nd generation } \\
\text { (3), } n=582\end{array}$ & $\begin{array}{c}\text { 3rd generation } \\
\text { (4), } n=66\end{array}$ & $(1) v s(2)$ & (2)vs(3) & (3)vs(4) & (1)vs(3) & $(1) v s(4)$ & $(2) v s(4)$ \\
\hline Body mass, kg & $69.1 \pm 10.2$ & $68.1 \pm 11.9$ & $67.7 \pm 9.0$ & $73.2 \pm 11.2$ & 0.792 & 0.991 & $<0.001$ & 0.802 & 0.024 & $<0.001$ \\
\hline Body fat, \% & $10.1 \pm 4.7$ & $11.1 \pm 5.9$ & $10.7 \pm 4.4$ & $12.9 \pm 4.5$ & 0.651 & 0.745 & $<0.001$ & 0.881 & $<0.001$ & $<0.001$ \\
\hline Body length, $\mathrm{cm}$ & $179.4 \pm 6.3$ & $177.8 \pm 8.7$ & $178.5 \pm 6.0$ & $180.8 \pm 7.0$ & 0.049 & 0.362 & $<0.001$ & 0.824 & 0.132 & $<0.001$ \\
\hline $\mathrm{CC}, \mathrm{cm}$ & $89.7 \pm 4.7$ & $90.3 \pm 5.9$ & $90.4 \pm 6.5$ & $93.5 \pm 2.8$ & 0.742 & 0.658 & $<0.001$ & 0.953 & $<0.001$ & $<0.001$ \\
\hline PI, arb. units & $23.0 \pm 13.3$ & $21.2 \pm 13.4$ & $22.2 \pm 13.6$ & $13.2 \pm 14.8$ & 0.952 & 0.610 & $<0.001$ & 0.981 & $<0.001$ & $<0.001$ \\
\hline $\mathrm{BPI}, \%$ & $91.1 \pm 4.6$ & $91.0 \pm 5.2$ & $91.4 \pm 3.6$ & $95.6 \pm 4.8$ & 0.981 & 0.455 & $<0.001$ & 0.980 & $<0.001$ & $<0.001$ \\
\hline $\mathrm{S}, \mathrm{cm}^{2}$ & $18677.7 \pm 1390.6$ & $18448.9 \pm 1533.1$ & $18448.6 \pm 1455.2$ & $19369.6 \pm 1347.0$ & 0.570 & 0.936 & $<0.001$ & 0.742 & $<0.001$ & $<0.001$ \\
\hline $\mathrm{BMI}, \mathrm{kg} / \mathrm{m}^{2}$ & $21.3 \pm 3.2$ & $21.3 \pm 2.4$ & $21.2 \pm 1.9$ & $21.9 \pm 2.1$ & 0.982 & 0.813 & 0.036 & 0.954 & 0.160 & 0.045 \\
\hline $\mathrm{MT} / \mathrm{S}, \mathrm{kg} / \mathrm{m}^{2}$ & $36.8 \pm 3.1$ & $36.8 \pm 2.8$ & $36.5 \pm 1.2$ & $37.3 \pm 2.0$ & 0.962 & 0.964 & $<0.001$ & 0.872 & 0.154 & 0.058 \\
\hline
\end{tabular}

Data presented as mean with standard deviation - M \pm SD.

$\mathrm{CC}$, chest circumference; PI, Pignet index; BPI, body proportionality index; S, body area; BMI, body mass index; MT/S, ratio of body mass to body area. 


\section{Discussion}

The results obtained in our work indicate that newcomers with the shortest period of residence in the conditions of the NorthEast of Russia were characterized by high Body Length indices, as well as young men of the 3rd generation. Whereas in the examinees of the 1st and 2nd generations this parameter had lower values, which reflects the U-shaped trend of the growth rate in the row from the 1st to the 4th group. The reduction in the body length observed in representatives of the first generation as compared to the surveyed migrants who arrived in the territory of Magadan Region from the more favorable climatic regions may be due to the deterioration of socio-economic and climaticgeographical conditions. J. Tanner (1982) noted in his studies the influence of unfavorable factors in childhood on growth processes by reducing their dimensionality [15].

It is also necessary to indicate the region-related features of the body length obtained in our work. Judging by the analysis of this indicator, the young men of Magadan Region are characterized by the highest numerical values, as compared to those surveyed on the territory of the Russian Federation and to young people living in other countries. The average body length of

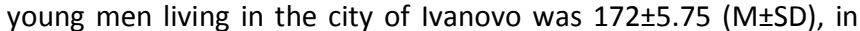
Kursk - 169.2 $\pm 0.67(\mathrm{M} \pm \mathrm{m})$, in Rostov-on-Don - 176.6 $\pm 0.75(\mathrm{M} \pm \mathrm{m})$, Naryan-Mar $-169.8 \pm 0.82(\mathrm{M} \pm \mathrm{m})$, in the city of Ulan-Ude -175.9 $(171.8,182.5)$ (data presented as median with lower and upper quartiles), , in the city of Krasnoyarsk $-176.7 \pm 0.56(\mathrm{M} \pm \mathrm{m})$, in the city Nizhny Novgorod $-175.8 \pm 0.61(\mathrm{M} \pm \mathrm{m})$, in Saratov $-175.9 \pm 0.64$ $(\mathrm{M} \pm \mathrm{m})$ [16]. From the given data it can be seen that the body length of young men of the city of Magadan is somewhat higher than that of their age mates from other cities of Russia. The average body length of 17-18 year old boys in China (Beijing) (the authors indicate that the results correspond to the final growth of an adult human, which fully agrees with our data) was $175.37 \mathrm{~cm}$ [11] which is slightly lower than that of their American age mates whose body length was $176.3 \mathrm{~cm}$ [12] but more than the 17-yearold subjects in European countries located at the same latitude as Beijing such as France $(174.1 \mathrm{~cm})$ [13], Italy $(174.48 \mathrm{~cm})$ and Spain $(175.3 \mathrm{~cm})$ and significantly higher than in Japan $(170.5 \mathrm{~cm})$ [11]. The obtained results indicate that the young men of Magadan are characterized by the highest body length indices, which on the whole distinguishes them from a number of other populations living both in different subjects of Russia and in other countries.

The tendency to increasing in the length of the body, which is found in young men with the longest period of residence (3rd generation), can be explained on the basis of the following positions. Firstly, at the present time, an increase in the growth rate in modern young people is seen as a reflection of the current progress of civilization. The positive dynamics of this somatometric characteristic is at the same time a good marker of this trend [17] and is widely used in sociological and economic studies as a measure of human well-being [5]. These statements find some confirmation in our study since the highest rates of increase in body length were recorded in representatives of the third generation. It should be emphasized that this is a newly formed population, and its representatives were born in the 2000s when in our country, and in the territory of Magadan Region particularly, there have been tendencies to improve the development of the social and economic system [18].

However, in the literature data there are facts of the compensatory effect of increase in body length, which are observed in populations in which the socioeconomic conditions were initially unfavorable. The tendencies of the secular trend are especially intense in the most backward and least developed populations and/or social strata, while the lower the initial value of the trait in the population, the more intensive its compensation [19]. It is also found that compensatory growth may be associated with systematic malnutrition [20]. These statements may be a consequence of the fact that in the 1990s, due to the so-called "cooling" of the governmental policy to the northern territories that coincided with Russia's transition to market relations, there was an economic decline in the regions of the Far East in general and in Magadan region, in particular [18]. These latter circumstances can be a definite explanation for such a pronounced dynamics of the increase in body length in modern young men (representatives of the third generation). Its numerical values exceed those observed in other regions of Russia as well as in other countries.

Analysis of body mass and chest circumference revealed an increase in these indicators in young men of the 3rd generation. It should be noted that this dynamics is synchronous, which together with the increase in body length does not lead to the formation of an asthenic somatotype which is typical for some populations of our country [16]. This fact is confirmed by a decrease in the numerical values of the Pignet Index which indicates an increase in the strength of the physique of the young males of the 4th group.

Body mass index (BMI) is a widely used indicator that reflects the state of the energy reserve in the human body and is related to the degree of obesity. At the same time, BMI is recommended by WHO as an indicator of the relative risk of development of type II diabetes and cardiovascular diseases [21]

Our study showed that in the 4th group the body mass index values like those of the 0 th, $1 \mathrm{st}$, and 2 nd generation were within the normative range for this trait. However, the third generation of young men showed an increase in such body values as the chest circumference with simultaneous increase in the body length, weight, and total body fat. The observed increase in the body fat component did not go beyond the normative range [22], which does not correspond to the worldwide trend, where the studies of the last decades have considered many developed countries to have the secular trend of the body length being no longer progressing while the average weight continues to grow and leads to obesity [23-26].

As it can be seen from the results of the study, in parallel with the increase in the longitudinal size of the body and girth characteristics, changes have also been observed in the proportion of the body build in modern young men - representatives of the third generation, which is most clearly manifested by an increase in the length of the legs of the subjects in relation to their bodies. The results obtained in our studies are similar to the data in which thwe body length changes within the secular trend occur due to changes in the leg length [2], mainly in the first two years of life [27]. The reverse trend according to which the increase in the body length occurs due to the relative shortening of the leg length and elongation of the trunk is considered as an indicator of unfavorable conditions for growth in the pre-pubertal period of ontogenesis [28].

The increase in the body area and the ratio of the body mass to the body area in the row from the 0th to the 3rd generation can be considered as an unfavorable trend of somatometric rearrangements, which leads to the stress of thermoregulatory mechanisms under the 
cold conditions [29] due to an increase in the body surface, which in turns leads to an increase in the heat loss [30].

Accounting for the fact that the term "secular trend" implies a growth and development trend and is defined as "changes in the growth and development of subsequent generations living in the same territory" [31], we can talk about the manifestation of these features in our studies, too. At the same time, the expressed positive variability of the growth indices was revealed in the young male subjects of the third generation, i.e. the group that have the longest experience of living in the northeast of Russia, whose representatives were born in the 2000s.

Thus, the comparative analysis of indicators of physical development demonstrated by young men who differ in terms of residence in the territory of Magadan region and were born in different decades has shown that modern young male subjects prove themselves to be higher in most anthropometric characteristics than their age-mates who have a shorter period of residence in the north. A region-related peculiarity in the formation of somatometric status of young men of the city of Magadan is established, which is expressed by longer body parts in comparison with those from other regions of the Russian Federation as well as with other countries. Together with the noted variability in somatometric characteristics, changes in the body proportion were established, which was seen in a pronounced increase in the length of the legs as well as the strength of the body build demonstrated by the boys of the third generation.

\section{Conclusion}

In general, the results of the study indicate ongoing secular trend processes in young male residents of Magadan region, which distinguishes our population from young men living in other regions where researchers report stabilization of the growth processes of modern youth in most countries of the world.

\section{Conflict of interest}

Author declares no conflict of interest.

\section{Funding}

The research was financed from the budget of the Scientific Center "Arktika" (Magadan, Russia).

\section{References}

1. Eaton DK, Kann L, Kinchen S, Shanklin S, Flint KH, Hawkins J, et al. Youth risk behavior surveillance - United States 2011. MMWR Surveill Summ 2012; 61(4): 1-162. https://www.ncbi.nlm.nih.gov/pubmed/22673000.

2. Tanner JM. Growth as a measure of the nutritional and hygienic status of a population. Horm Res 1992; 38(1): 106-115. https://doi.org/10.1159/000182580.

3. Schell LM, Knutson KL, Bailey S. Chapter 10 - Environmental effects on growth. In: Human Growth and Development, 2nd edition. NY, USA: Academic Press, 2012: 245-286. https://doi.org/10.1016/b978-0-12383882-7.00010-6.

4. Tanner JM. Growth as a mirror of the condition of society: secular trends and class distinctions. Acta Paediatr Jpn 1987; 29(1): 96-103. https://doi.org/10.1111/i.1442-200x.1987.tb00015.x

5. Steckel RH. Heights and human welfare: recent developments and new directions. Explorations Econ Hist 2009; 46(1): 1-23. https://doi.org/10.1016/i.eeh.2008.12.001.
6. Haas JD, Campirano F. Interpopulation variation in height from 7 to 18 years of age. Food and Nutrition Bulletin 2006; 27(4): S212-S223. https://doi.org/10.1177/15648265060274s505.

7. WHO Multicentre Growth Reference Study Group. Assessment of differences in linear growth among populations in the WHO Multicentre Growth Reference Study. Acta Pædiatr Suppl 2006; 450 56-65. https://doi.org/10.1111/j.1651-2227.2006.tb02376.x.

8. Tobias PV. On the increasing stature of the Bushmen. Anthropos 1962 57: 801-810. https://doi.org/10.2307/2794792.

9. Wolanski N, Malik SL. Human ecology: the need for a new emerging science. Stud Hum Ecol 1984; 5: 7-13.

10. Lasker GW. Human biological adaptability. Science 1969; 166: 14801486. https://doi.org/10.1126/science.166.3912.1480.

11. Fan W, Qian Y. Long-term health and socioeconomic consequences of early-life exposure to the 1959-1961 Chinese Famine. Soc Sci Res 2015; 49: 53-69. https://doi.org/10.1016/i.ssresearch.2014.07.007.

12. McDowell MA, Fryar CD, Ogden CL. Anthropometric reference data for children and adults: United States, 1988-1994. Vital Health Stat 11 2009; (249): 1-68. https://www.ncbi.nlm.nih.gov/pubmed/19642512.

13. Herpin N. Love, careers, and heights in France, 2001. Econ Hum Bio 2005; 3(3): 420-449. https://doi.org/10.1016/j.ehb.2005.04.004.

14. Borovikov VP. Statistica. The art of analyzing data on a computer: for professionals. SPb, Russia: Piter, 2003. Russian.

15. Tanner JM, Hayashi T, Preece MA, Cameron N. Increase in length of leg relative to trunk in Japanese children and adults from 1957 to 1977 comparison with British and with Japanese Americans. Ann Hum Biol 1982; 9: 411-423. https://doi.org/10.1080/03014468200005951.

16. Physical development of children and adolescents of the Russian Federation. Materials collection (issue VI). A.A. Baranova, V.R. Kuchma, eds. Moscow, Russia: Publishing House "Pediatr", 2013. Russian. http://riskprom.ru/ ld/3/375 detiRossii fiz .pdf.

17. Vignerova J, Brabec M, Blaha P. Two centuries of growth among Czech children and youth. Econ Hum Biol 2006; 4: 237-252. https://doi.org/10.1016/j.ehb.2005.09.002.

18. Strategy of socio-economic development of the Far East and the Baikal region for the period until 2025 approved by the Government of the Russian Federation on December 28th, 2009. No. 2094 http://www.garant.ru/products/ipo/prime/doc/6632462.

19. Wolanski N. Secular trend, secular changes, or long-term adaptational fluctuations? Acta Medica Auxologica 1985; 17: 7-19. https://doi.org/10.1007/978-1-4757-0743-4_25.

20. Morgan SL, Richer and Taller: stature and living standards in China, 1979-1995. China J 2000; 44: 1-39. https://doi.org/10.2307/2667475.

21. Kinge JM. Body mass index and employment status: a new look. Econ Hum Biol 2016; 22: 117-125. https://doi.org/10.1016/j.ehb.2016.03.008.

22. Robergs RA, Roberts SO. Exercise physiology. Exercise, performance, and clinical application. St. Louis: Mosby - Year Book, 1997. https://doi.org/10.1097/00001416-199501000-0001.

23. Cardoso HF, Caninas M. Secular trends in social class differences of height, weight and BMI of boys from two schools in Lisbon, Portugal (1910-2000). Econ Hum Biol 2010; 8: 111-120. https://doi.org/10.1016/j.ehb.2009.04.005

24. Cardoso HF, Padez C. Changes in height, weight, BMI and in the prevalence of obesity among 9- to 11-year-old affluent Portuguese schoolboys, between 1960 and 2000. Ann Hum Biol 2008; 35: 624-638. https://doi.org/10.1080/03014460802464200.

25. Komlos J, Lauderdale BE. The mysterious trend in American heights in the 20th century. Ann Hum Biol 2007; 34: 206-215. https://doi.org/10.1080/03014460601116803.

26. Smpokos EA, Linardakis M, Papadaki A, Kafatos A. Secular changes in anthropometric measurements and blood pressure in children of Crete, Greece, during 1992/93 and 2006/07. Prev Med 2011; 52: 213217. https://doi.org/10.1016/i.ypmed.2011.02.006. 
27. Moradi A. Nutritional status and economic development in subSaharan Africa, 1950-1980. Econ Hum Biol 2010; 8: 16-29. https://doi.org/10.1016/j.ehb.2009.12.002.

28. Bogin BA, Varela Silva M, Leg Length IO. Body proportion, and health: a review with a note on beauty. Int J Environ Res Public Health 2010; 7(3): 1047-1075. https://doi.org/10.3390/ijerph7031047.

29. Averyanova IV, Maksimov AL, Vdovenko SI. The dynamics of some somatometric indicators in young male residents of the North-East of Russia for the period 1975-2014. Morphology 2016; 150(5): 58-62. Russian. https://elibrary.ru/item.asp?id=27639093.

30. Bogin B. Patterns of human growth. Cambridge: Cambridge University Press, 1988. https://doi.org/10.1002/ajhb.1310010318

31. Ulijaszek SJ. Secular trend in birthweight among the Purari delta population, Papua New Guinea. Ann Hum Biol 2001; 28(3): 395-398. https://doi.org/10.1080/030144601300119061.

\section{Authors:}

Inessa V. Averyanova - PhD, Senior Researcher, Laboratory for Physiology of Extreme States, Scientific Center "Arktika", Far Eastern Branch of the Russian Academy of Sciences, Magadan, Russia. http://orcid.org/0000$\underline{0002-4511-6782}$ 